\title{
Three-Dimensional Atom Probe Analysis of Carbon Distribution in Low-Temperature Bainite
}

\author{
M. Peet ${ }^{*}$, S. S. Babu ${ }^{\dagger}$, M. K. Miller ${ }^{\dagger}$ and H. K. D. H. Bhadeshia* \\ 'Department of Materials Science and Metallurgy, University of Cambridge, \\ Pembroke Street, Cambridge, United Kingdom \\ ${ }^{\dagger}$ Metals and Ceramics Division, Oak Ridge National Laboratory, Oak Ridge, TN \\ 37831, United States of America
}

\begin{abstract}
A bainitic microstructure with fine ferrite plates $(20$ to $40 \mathrm{~nm}$ ) in a matrix of high-carbon retained austenite, obtained by isothermal transformation at $200^{\circ} \mathrm{C}$, was characterized with an energy-compensated optical position-sensitive three-dimensional atom probe. The average carbon concentration in the austenite was found to be $8.0 \pm 1.6$ at.\% and in the bainitic ferrite $1.1 \pm 0.7$ at. $\%$. The latter concentration is much higher than expected from paraequilibrium between austenite and ferrite, and the austenite carbon concentration is found to be slightly higher than the $\mathrm{T}_{0}$ limit.
\end{abstract}

\section{Introduction}

A high-strength steel has recently been developed by isothermal transformation of austenite to produce very thin plates $(20-40 \mathrm{~nm})$ of bainitic ferrite. This microstructure is achieved by transformation at temperatures as low as $200^{\circ} \mathrm{C}$ [1-4] for time periods as long as many days. The low transformation temperature is achieved by the use of a high average carbon concentration and to some extent, substitutional solutes such as manganese. The silicon concentration is such that the precipitation of carbides from austenite is prevented during the bainite reaction. The microstructure following isothermal transformation is quite simple, a mixture of bainitic ferrite and carbon-enriched retained austenite. The austenite occurs either as films between the ferrite plates or as fine blocks bounded by bainite sheaves [1-4].

X-ray diffraction analysis of the retained austenite has shown that it is enriched in carbon to a concentration close to $\mathrm{T}_{0}$ boundary, as expected from the incomplete reaction phenomenon [5]. The $T_{0}$ boundary on a temperature versus carbon concentration plot is the locus of points at which the Gibbs free energies of austenite and ferrite of identical composition are equal. The X-ray analysis also revealed a considerable supersaturation of carbon in the bainitic ferrite [1-4]. Similar supersaturation has been measured previously using atom probe analysis [6,7] and convergent beam electron diffraction analysis [8] in low-carbon steels. This supersaturation was attributed to the trapping of carbon at the dislocations [5] in the bainitic ferrite.

The compositional studies of the new high-carbon bainite of interest have been performed using X-ray lattice parameter measurements. They represent coarse measurements whereas the scale of the microstructure is very fine. It was therefore decided to use the atom probe to obtain more detailed information, particularly of the fine scale distribution of carbon. The three-dimensional atom-probe used has the ability to collect large quantities of atomic data, which can then be compared against theory. 


\section{Experimental}

The composition of the steel is given in Table I. These samples were prepared from a billet of $25 \mathrm{~kg}$. After casting the ingot was cooled to ambient temperature, then hot rolled into plate $40 \mathrm{~mm}$ thick and $75 \mathrm{~mm}$ wide. Sections of approximately $40 \mathrm{~mm}$ x $40 \mathrm{~mm}$ x $75 \mathrm{~mm}$ were machined, homogenized for $48 \mathrm{~h}$ at $1200^{\circ} \mathrm{C}$. Care was taken to avoid martensite formation by slowly cooling the sample after each heat treatment. Rods of $3 \mathrm{~mm}$ in diameter were then made by electrical spark erosion and sealed in quartz tubes with an argon atmosphere at 0.9 bar. They were then austenitized by placing in an oven preheated to $500^{\circ} \mathrm{C}$ followed by continuous heating to $1000^{\circ} \mathrm{C}$ where they were held at that temperature for $15 \mathrm{~min}$. After austenitization, the rods were removed from the quartz tubes and allowed to cool to the isothermal transformation temperature of $200^{\circ} \mathrm{C}$ and were held at that temperature for 12 days. The heat treatment is based on a measured TTT diagram (see Fig. 1a) from the same alloy [9]. Detailed transmission electron microscopy on the present microstructure has been reported elsewhere [9] but a typical microstructure is shown in Fig. 1b. Atom probe tomography characterizations were performed in the ORNL energy-compensated optical position-sensitive atom probe (ECOPOSAP). The experiments were performed at a specimen temperature of $60 \mathrm{~K}$, a pulse repetition rate of $1.5 \mathrm{kHz}$, and a pulse fraction of $20 \%$ of the standing voltage. The data were analyzed using the standard procedures given in the reference [10].

Table I: Chemical composition.

\begin{tabular}{lllllllllll}
\hline & $\mathrm{C}$ & $\mathrm{Si}$ & $\mathrm{Mn}$ & $\mathrm{Mo}$ & $\mathrm{Cr}$ & $\mathrm{V}$ & $\mathrm{Al}$ & $\mathrm{P}$ & $\mathrm{S}$ & $\mathrm{Fe}$ \\
\hline Wt.\% & 0.75 & 1.63 & 1.95 & 0.28 & 1.48 & 0.1 & 0.01 & 0.003 & 0.003 & Balance \\
At.\% & 3.34 & 3.10 & 1.90 & 0.16 & 1.52 & 0.1 & 0.02 & 0.005 & 0.005 & Balance \\
\hline
\end{tabular}

\section{Results and Discussion}

A typical atom probe result is shown in Fig. 2. The atom map shows a projection of the carbon atom positions in thee dimensions obtained from a large data set. The corresponding concentration profiles from a selected volume of $(5 \mathrm{~nm} \square 5 \mathrm{~nm} \square 340 \mathrm{~nm})$ are shown in Fig. 3. The error bars for each concentration point are calculated based on the procedures given in reference 10. The measurements show alternating carbon-enriched and carbon-depleted regions. The variations in the degree of enrichment are large. It is important to note that the carbon fluctuations in the austenite and ferrite do not correlate with substitutional solute concentrations. The measured fluctuations of $\mathrm{Cr}$, Si and $\mathrm{Mn}$ shown in Fig. 3 are within the calculated uncertainties and consistent with the substitutional lattice being configurationally frozen during transformation.

As the atom probe analyses generally do not give crystallographic information, carbon enrichment beyond the average value of 3.3 at. \% is assumed to represent a region of austenite. This indicates the presence of austenite phases at the marked distances. The morphology of these ferrite and austenite regions can be compared to a typical transmission electron microscope image shown in Fig. 1b. There is striking similarity of concentration fluctuations with the scale of the bainitic ferrite plates and austenite films.

The enrichment of austenite ( $>8$ at.\%) with carbon is expected when some of the excess carbon partitions from the bainitic ferrite following transformation [5]. The maximum enrichment of carbon in the austenite at $73 \mathrm{~nm}$ distance was found to increase to a maximum of 12 at.\% on making the selected volume perpendicular to the austenite-ferrite interface. 
The data from the ferrite regions also show carbon enrichment that is in agreement with previous X-ray studies [1-4]. The presence of excess carbon in the ferrite is a consequence of the displacive mode of transformation, and its retention within the ferrite is thought to be associated with the stability of carbon within defects in the ferrite [5]. These defects trap the carbon atoms as originally suggested by Kalish and Cohen [11]. The trapping prevents the carbon from partitioning into austenite and from precipitating within the ferrite. There are detailed variations in the carbon within the austenite, for example at 100 to $150 \mathrm{~nm}$ [see Fig. $3]$, which are as yet unexplained.

Another example from a small data set sampling austenite and ferrite is shown Fig. 4 and 5. As in Fig. 2, this atom map is the projected image of the three-dimensional position of carbon atoms. Fig. 5 shows the concentration profile across the austenite and ferrite phases, with a sampling volume (marked in the atom image in Fig. 4) approximately perpendicular to the austenite-ferrite interface. These data show that the average carbon concentration of austenite is $8.0 \pm 1.6$ at. $\%$ and of ferrite is $1.1 \pm 0.7$ at. $\%$. The carbon concentration variation across the interface is not sharp. Similar to the results in Fig. 2 and 3, there is no correlation between austenite and ferrite carbon concentrations to any substitutional solute concentration. There is no partitioning of substitutional elements during the bainite transformation.

The measured data are compared with paraequilibrium phase diagram calculated for the steel (Table 1) [12]. The calculated and the measured ferrite and austenite compositions are compared in Fig. 6a. The calculated paraequilibrium concentration of carbon in ferrite is so low that it overlaps with the y-axis for the scales illustrated. The calculations show that there is excess carbon in the ferrite, well beyond the 0.05 at. \% expected from paraequilibrium with austenite at $200^{\circ} \mathrm{C}$. The average austenite carbon concentration is also somewhat higher than that of expected $\mathrm{T}_{0}$ limit. To evaluate the sensitivity of thermodynamic information and $\mathrm{T}_{0}$ point at $200^{\circ} \mathrm{C}$, further calculations were performed using ThermoCalc ${ }^{\circledR}$ software [13] and Thermo-Tech Iron database [14]. These calculations also show [see Fig. 6b] that the austenite carbon concentration is higher than the predicted $\mathrm{T}_{0}$ concentration. To provide a better perspective of these comparisons, histograms of measured carbon concentrations from figures 3 and 5 are shown in Fig. $6 c$. The data show that the measured austenite carbon concentrations vary over a wide range. Earlier X-ray diffraction studies of the austenite composition showed good agreement with $\mathrm{T}_{0}$ at $200^{\circ} \mathrm{C}[5,6]$. These are average results whereas, the atom probe results has a much higher spatial resolution. Nevertheless, the lower limit of austenite carbon concentration measured in atom probe is closer to the $\mathrm{T}_{0}$ curve, which may be considered as agreement with theoretical models for bainitic transformation. The reasons why the concentration may be somewhat in excess of $\mathrm{T}_{0}$ have been discussed previously [5,6]. Carbon can continue to partition into isolated regions of austenite although transformation to bainite cannot occur once the concentration reaches that given by the $\mathrm{T}_{0}$ curve.

\section{Conclusions}

An energy compensated optical position sensitive atom probe was used to analyze the nanoscale distribution of carbon and other substitutional solutes in a low temperature bainitic microstructure consisting of a mixture of bainitic ferrite plates in a retained austenite matrix. Atom probe microanalysis showed a wide distribution of carbon concentrations in both ferrite and austenite. The measured average carbon concentration in the austenite was $8.0 \pm 1.6$ at.\% and the maximum concentration was $12.0 \pm 1.3$ at. $\%$. The measured average carbon concentration in bainitic ferrite was $1.1 \pm 0.7$. In ferrite regions close to the austenite, the maximum ferrite carbon concentration was $1.8 \pm 0.4$ at. $\%$. The ferrite carbon concentrations are higher than the expected paraequilibrium solubility levels. The results are consistent with 
previous atom-probe data on low carbon steels and confirm the X-ray data, which indicated excess carbon to persist in bainitic ferrite.

\section{Acknowledgements}

The authors are grateful to the Engineering and Physical Sciences Research Council, CORUS and The Worshipful Company of Ironmongers for supporting this research. Research at the Oak Ridge National Laboratory SHaRE User Center was sponsored by the Division of Materials Sciences and Engineering, U.S. Department of Energy, under contract DE-AC0500OR22725 with UT-Battelle, LLC. The authors also thank Dr. Roger Jaramillo of Oak Ridge National Laboratory for helpful discussions on this paper.

\section{References}

1. Caballero FG, Bhadeshia HKDH, Mawella KJA, Jones DG and Brown P, Materials Science and Technology 2002; 18; 279-284

2. Garcia-Mateo C, Caballero FG and Bhadeshia, HKDH, ISIJ International 2003; 43; $1238-1243$

3. Garcia-Mateo C, Caballero FG, and Bhadeshia, HKDH, Journal de Physique IV 2003; 112; part 1, 285-288

4. Garcia-Mateo C, Caballero FG, and Bhadeshia, HKDH, ISIJ International 2003; 43; 1821-1825

5. Bhadeshia, HKDH, "Bainite in Steels," $2^{\text {nd }}$ Edition, IOM Communications Ltd, London, SW1Y 3DB, 2001

6. $\quad$ Bhadeshia, HKDH, Waugh AR, Acta Metall 1982; 30; 775-784

7. Stark I, Smith GDW, and Bhadeshia, HKDH, Metall. Trans. A, 1990; 21A, 837-844

8. Zhang MX and Kelly PM, Materials Characterization 1998; 40; 159-168

9. F. G. Caballero, H. K. D. H. Bhadeshia, K. J. A. Mawella, D. G. Jones, and P. Brown, Mater. Sci. Technol., 2002; 18, 279-284

10. Miller MK “Atom Probe Tomography, Analysis at the atomic level," Kluwer Academic / Plenum Publishers, New York, 2000

11. Kalish D and Cohen M, Materials Science and Engineering, 1970; 6; 156-166

12. Bhadeshia, HKDH, Metal Science; 1982; 16; 159-165

13. Andersson JO, Helander T, Hoglund L, and Sundman B, CALPHAD, 2002; 26; 273312

14. Thermotech Fe-Data Thermodynamic Database, Thermotech Ltd / Sente Software Ltd., Surrey Technology Centre, 40 Occam Road, GU2 7YG, UNITED KINGDOM 
Scripta Materialia Vol. 50, 2004, 1277-1281

\section{Figures}
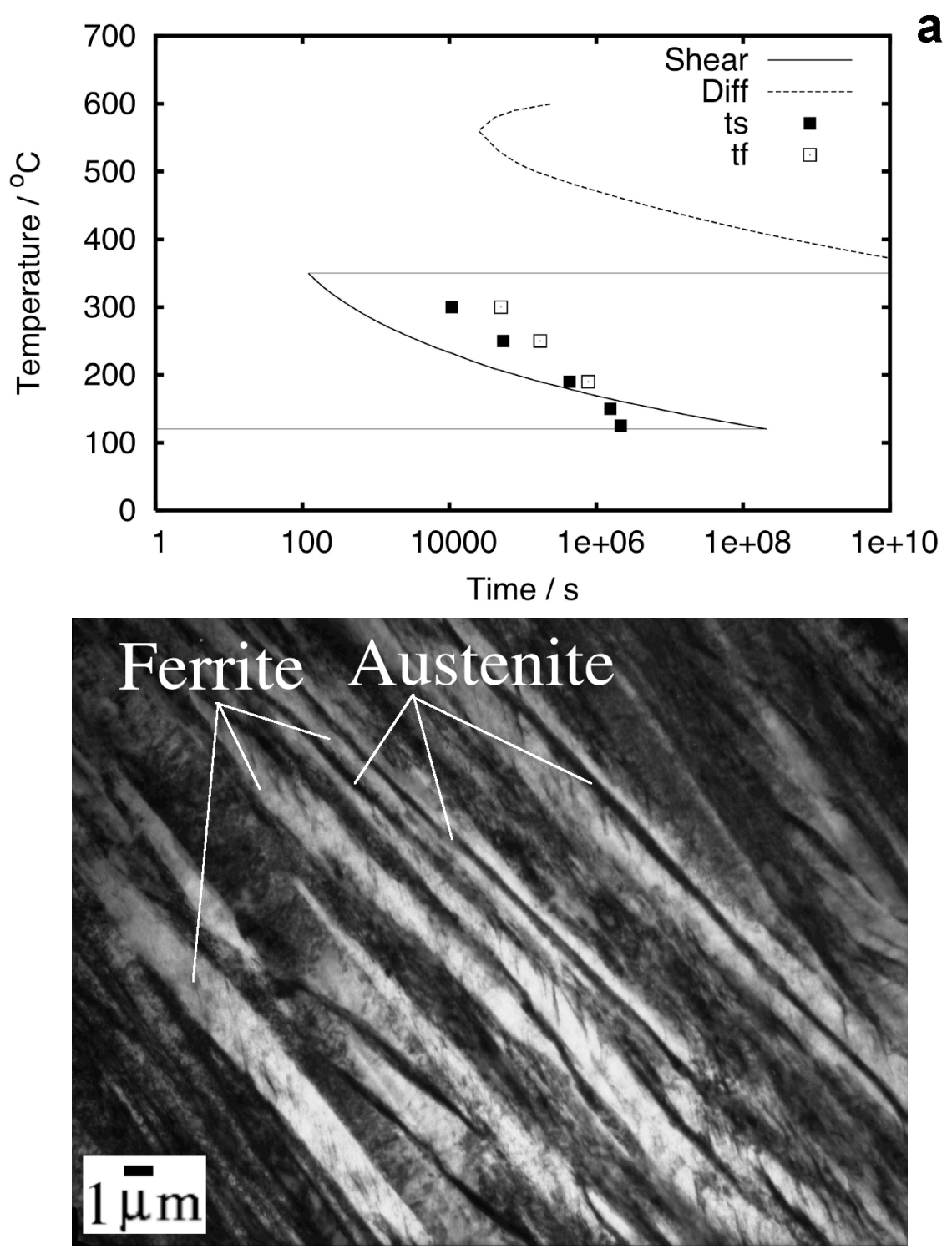

Fig. 1a Experimentally measured time-temperature-transformation (TTT) diagrams [9] and calculated TTT diagram [12] for the steel used. Transformation occurs to bainitic microstructure at $200^{\circ} \mathrm{C}$ during 11 days at temperature. (b) Transmission electron micrograph of the sample after isothermal holding at $200^{\circ} \mathrm{C}$ for more than 12 days showing ferrite plates (bright contrast) separated by films of retained austenite (dark contrast). 
Scripta Materialia Vol. 50, 2004, 1277-1281

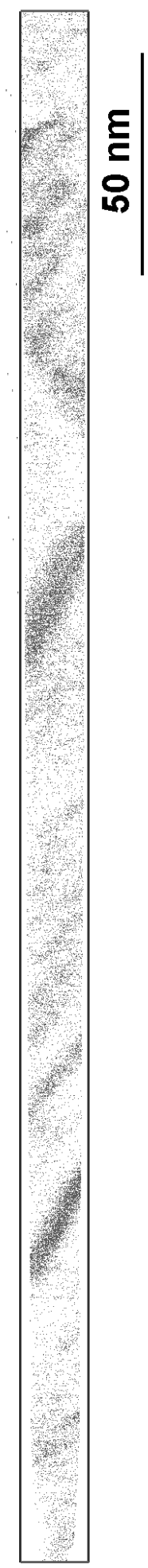

Fig. 2 Project atom map image obtained on a large data set showing the alternating regions of enriched carbon (austenite) and carbon depleted (bainitic ferrite) regions. 

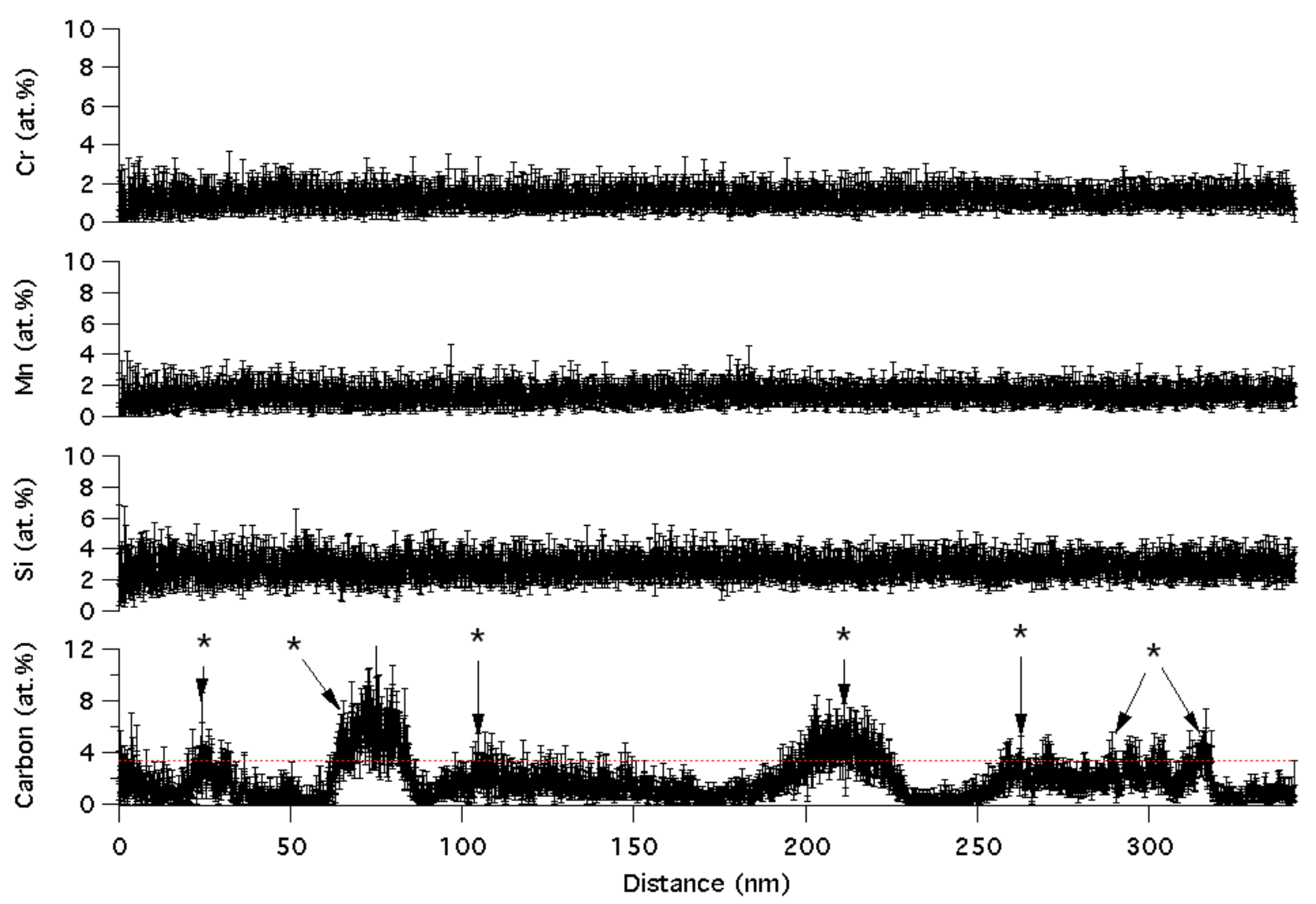

Fig. 3 Concentration profiles and associated errors for each data point from the data shown in Fig. 2. The data clearly shows that the fluctuations in carbon concentrations are significant in ferrite and austenite. The dotted line overlapped in the carbon concentration profile corresponds to nominal concentration of the steel. It is important to note that is no corresponding concentration fluctuations in the substitutional element concentration. 


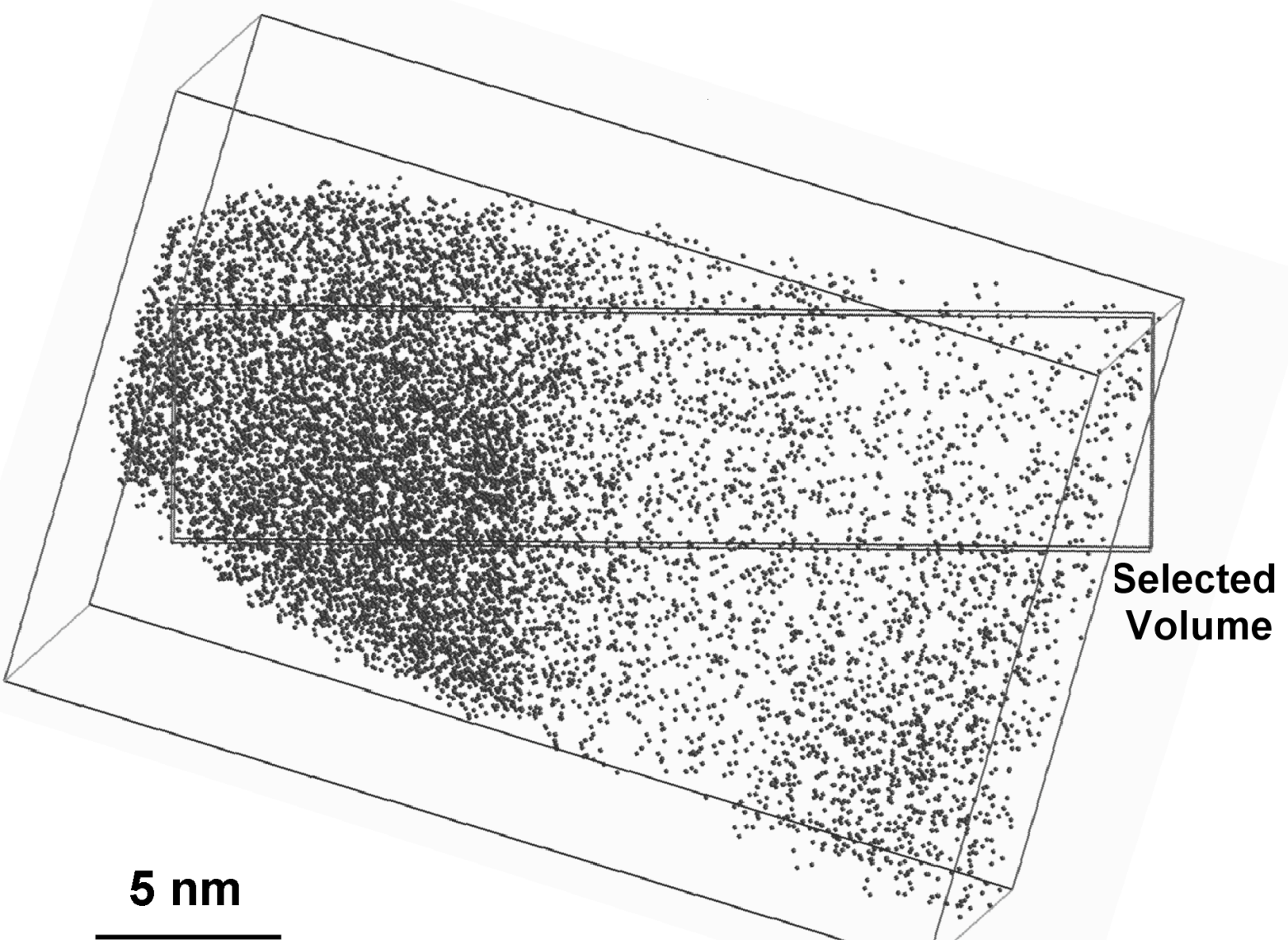

Fig. 4 Atom map image obtained on another data set shows the austenite and ferrite regions. The concentration profiles from the selected volume are shown in Fig. 5 
Scripta Materialia Vol. 50, 2004, 1277-1281
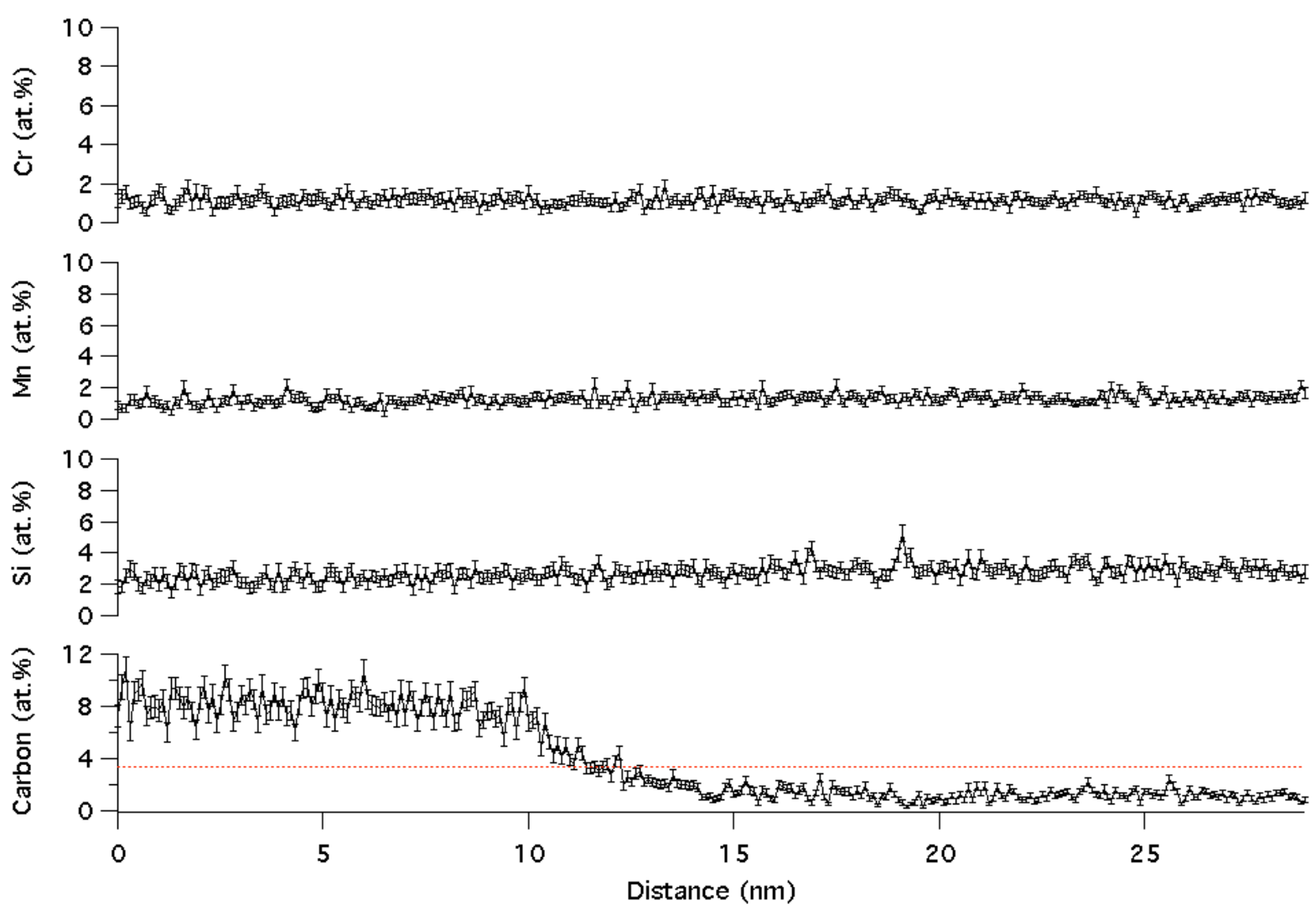

Fig. 5 Concentration profiles obtained from a selected volume marked in the atom map image of Fig. 4 are shown. The dotted line overlapped in the carbon concentration profile corresponds to nominal concentration of the steel. 


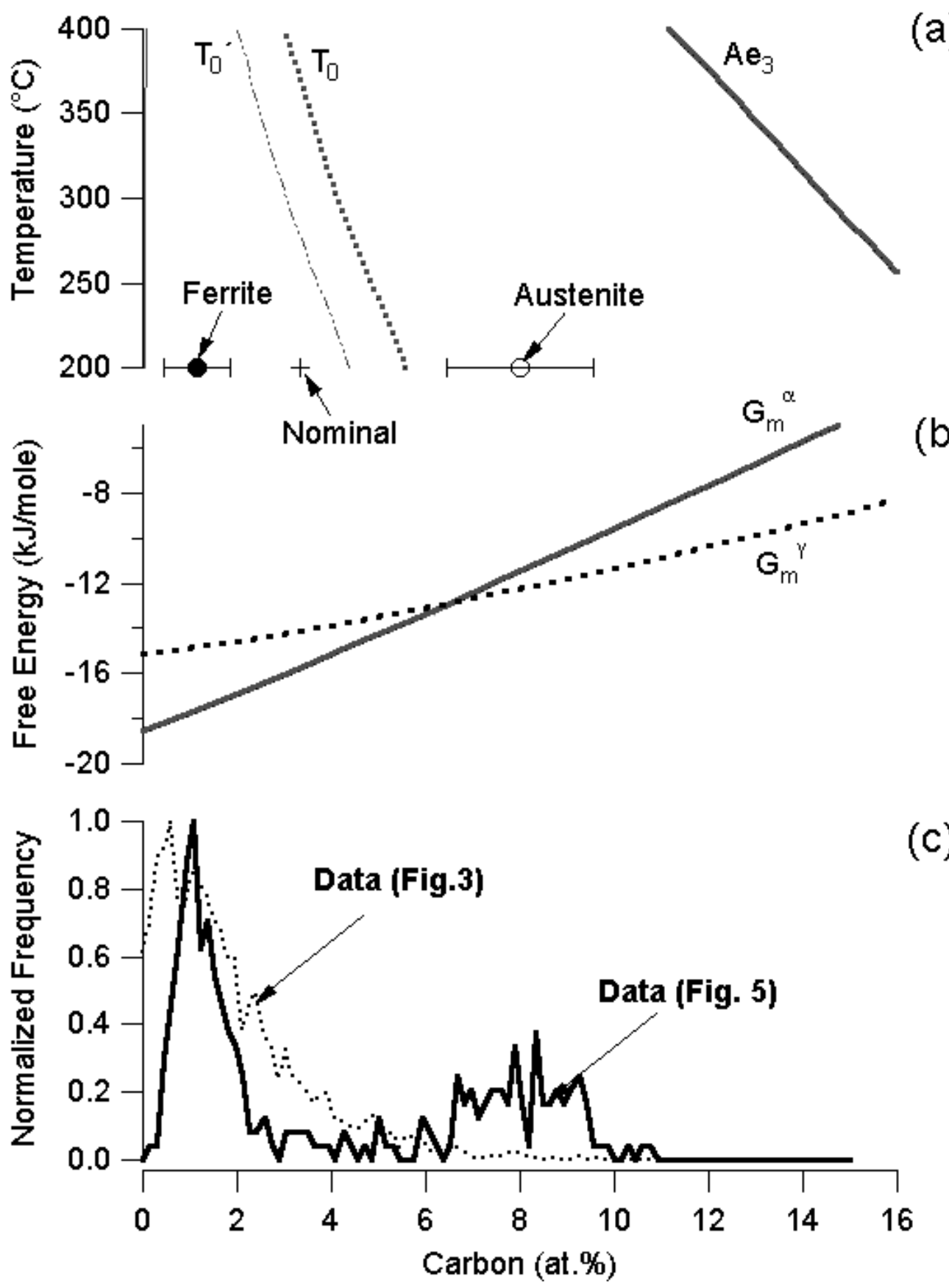

Fig. 6 ( $a$ ) The measured atom probe data are compared with calculated paraequilibrium phase diagram for the steel used in this investigation (b) Calculated variation of molar Gibbs free energy of austenite and ferrite for the same steel at $200^{\circ} \mathrm{C}$ shows that the measured austenite carbon concentration is slightly higher than that of expected $\mathrm{T}_{0}$ limit. (c) Histogram of measured carbon concentrations from the dataset shows that the ferrite and austenite carbon concentrations vary to a greater extent. 